\title{
Development of Optical Mesosphere Thermosphere Imagers (OMTI)
}

\author{
K. Shiokawa ${ }^{1}$, Y. Katoh ${ }^{1}$, M. Satoh ${ }^{1}$, M. K. Ejiri ${ }^{1}$, T. Ogawa ${ }^{1}$, T. Nakamura ${ }^{2}$, T. Tsuda ${ }^{2}$, and R. H. Wiens ${ }^{3}$ \\ ${ }^{1}$ Solar-Terrestrial Environment Laboratory, Nagoya University, Toyokawa, Aichi, Japan \\ ${ }^{2}$ Radio Atmospheric Science Center, Kyoto University, Uji, Kyoto, Japan \\ ${ }^{3}$ Center for Research in Earth and Space Science, York University, Ontario, Canada
}

(Received August 10, 1998; Revised December 2, 1998; Accepted April 1, 1999)

\begin{abstract}
The Optical Mesosphere Thermosphere Imagers (OMTI) have been developed to investigate the dynamics of the upper atmosphere through nocturnal airglow emissions. The OMTI consist of an imaging Fabry-Perot interferometer, three all-sky cooled-CCD cameras, three tilting photometers, and a Spectral Airglow Temperature Imager (SATI) with two container houses to install them in. These instruments measure wind, temperature and 2-dimensional airglow patterns in the upper atmosphere at multi-wavelengths of OI $(557.7 \mathrm{~nm}$ and $630.0 \mathrm{~nm}), \mathrm{OH}(6-2) \mathrm{bands}_{2} \mathrm{O}_{2}$ $(0,1)$ bands, and $\mathrm{Na}(589.3 \mathrm{~nm})$, simultaneously. Examples of the data are shown for the cameras, the photometers, and the SATI based on the airglow observation at a mid-latitude station in Japan. Good correlation of the photometer and SATI observations is obtained. A comparison is shown for small- and large-scale wave structures in airglow images at four wavelengths around the mesopause region using four cooled-CCD cameras. We found an event during which large-scale bands, small-scale row-like structures, and large-scale front passage occur simultaneously.
\end{abstract}

\section{Introduction}

Nocturnal airglow emissions give useful information on the study of the dynamics and chemistry of the upper atmosphere. Rotational temperature of atmospheric molecular constituents can be obtained by photometric measurement of airglow band emissions (e.g., Meriwether, 1975; Takahashi et al., 1989; Wiens et al., 1991, 1995; Fagundes et al., 1997). Doppler wind and temperature of the upper atmosphere are obtained by high-resolution interferometric measurements (e.g., Killeen and Roble, 1988, Rees et al., 1990; Conde and Smith, 1995; Hernandez and Roble, 1995; Dyson et al., 1997).

Furthermore, recent development of cooled-CCD detector makes it possible to detect spatial patterns in airglow emissions with a high-sampling rate of a few minutes per image. The images show various types of short-period wave structures which are probably caused by atmospheric gravity waves (e.g., Hecht and Walterscheid, 1991; Taylor and Hill, 1991; Taylor et al., 1995a, 1997, 1998). Simultaneous imaging observations of several airglow layers are very important to study vertical propagation of these waves. Such observations have not been done sufficiently yet, since an all-sky camera takes airglow images at several wavelengths by changing filters. Moreover, simultaneous observations of wind, temperature, and airglow images are needed to study the dynamics of the short-period waves.

The Optical Mesosphere Thermosphere Imagers (OMTI) were introduced by the Solar-Terrestrial Environment Laboratory, Nagoya University in 1997 in order to measure airglow variation patterns, horizontal wind, and temperature

Copy right (C) The Society of Geomagnetism and Earth, Planetary and Space Sciences (SGEPSS); The Seismological Society of Japan; The Volcanological Society of Japan; The Geodetic Society of Japan; The Japanese Society for Planetary Sciences. at several airglow layers simultaneously using three all-sky cameras and several interferometers with cooled-CCD detectors. In this paper, we show details of the instrumentation and initial results of the mid-latitude airglow observations near the mesopause region.

\section{Instrumentations}

Figure 1 shows a schematic picture of the OMTI system. The OMTI consists of a Fabry-Perot interferometer, three allsky cameras, three tilting photometers, and a Spectral Airglow Temperature Imager (SATI). These instruments are set in two air-conditioned container houses with several personal computers and a SUN workstation. Pictures of these instruments are shown in Fig. 2. The operations of the cameras, photometers, and SATI are fully automated by the personal computers. The data from these instruments can be copied from remote stations through a computer network.

The imaging Fabry-Perot interferometer measures neutral wind vectors and temperatures at three different altitudes simultaneously. Three cooled-CCD cameras with liquid nitrogen dewars are used as detectors. An all-sky airglow image is divided into three wavelengths $(557.7 \mathrm{~nm}(\mathrm{OI}), 630.0 \mathrm{~nm}$ $(\mathrm{OI})$, and $839.9 \mathrm{~nm}(\mathrm{OH})$ ) by two dichroic filters, passed through three band-pass filters, and detected by the cameras. The etalon has a clear aperture size of $116 \mathrm{~mm}$ with a cavity spacing of $15 \mathrm{~mm}$ (Queensgate ET116). It is set in a sealed cell to avoid fluctuation of the spacing due to the changes of pressure and humidity. Input light from a fish-eye lens passes through the etalon with a maximum angle of 0.7 (deg). Details of this instrument and its performance will be published elsewhere in the future.

The SATI measures intensities and rotational temperatures of $\mathrm{O}_{2}$ Atmospheric (0-1) P branch and $\mathrm{OH}$ Meinel (6-2) Q branch emissions using the technique of interference filter 
Container A (W2.4 $\times \mathrm{L} 6 \times \mathrm{H} 2.6 \mathrm{~m})$

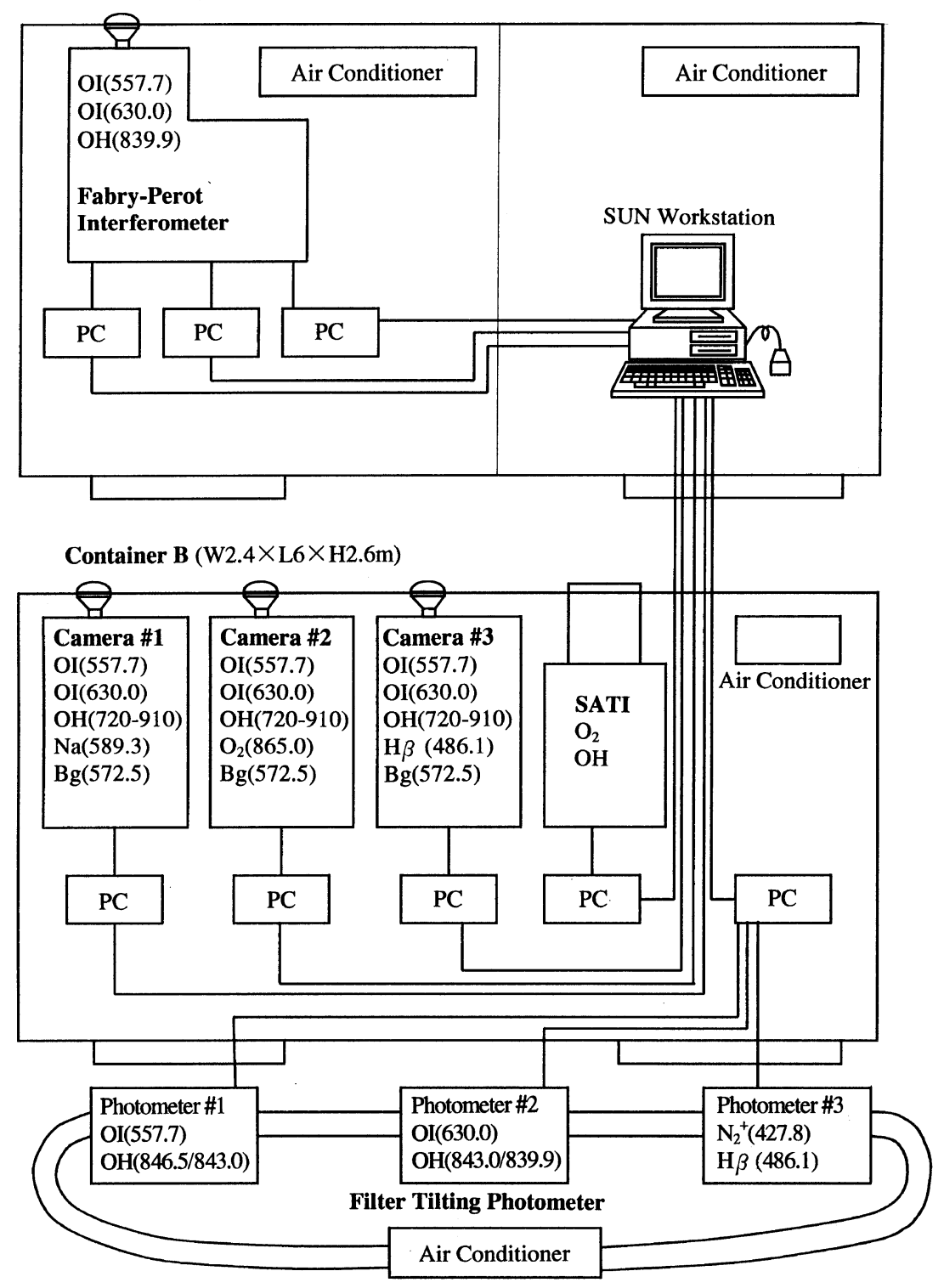

Fig. 1. Schematic diagram of the Optical Mesosphere Thermosphere Imagers (OMTI).

spectral scanning with a cooled-CCD detector. The technique was firstly developed by the Mesopause Oxygen Rotational Temperature Imager (MORTI) and the present implementation is described by Wiens et al. (1997). The integration time for each emission is $2 \mathrm{~min}$. By changing band-pass filters, the SATI measures the intensities and temperatures of $\mathrm{O}_{2}$ and $\mathrm{OH}$ band emissions with a time resolution of $4 \mathrm{~min}$. The SATI has an annular field-of-view in the sky with a radius of $30^{\circ} \pm 3.5^{\circ}$ zenith angle centered on the zenith. Temperature and intensity of each emission are obtained for twelve azimuthal sectors.

In the following two sections we describe the performance of the all-sky cameras and the tilting filter photometers.

\subsection{All-sky cameras}

Figure 3 is a schematic diagram showing one of the camera system. The fish-eye ( $f=24 \mathrm{~mm}$ ) lens at the head of the camera has a field of view of $180^{\circ}$. This front lens can be replaced by $45 \mathrm{~mm}$ and $80 \mathrm{~mm}$ lenses for narrower fields of view of $76^{\circ}$ and $47^{\circ}$, respectively. The shutter is controlled by the personal computer, while it is designed to remain closed when daylight is detected by the CdS optical sensor as a fail-safe system. The filter wheel contains five 3-inch filters the characteristics of which are listed in Table 1. The incident light from the front lens passes through the telecentric optics made by KEO Consultants and is focused on the thinned and back-illuminated $512 \times 512$ cooled-CCD detectors (Hamamatsu C4880). The image data from the cameras are recorded on a $640 \mathrm{MB}$ optical disk through the computer and are also accessible through a computer network. The whole system is backed up by a power supply that can run for more than $10 \mathrm{~min}$.

The absolute sensitivities at the $(256,256)$ pixel (around the center of image) are also listed in Table 1. Details of the calibration to obtain these values are shown by Shiokawa et al. (1999). The sensitivities vary from 0.03 to 0.05 (counts/R/s) depending on the cameras and filters. 


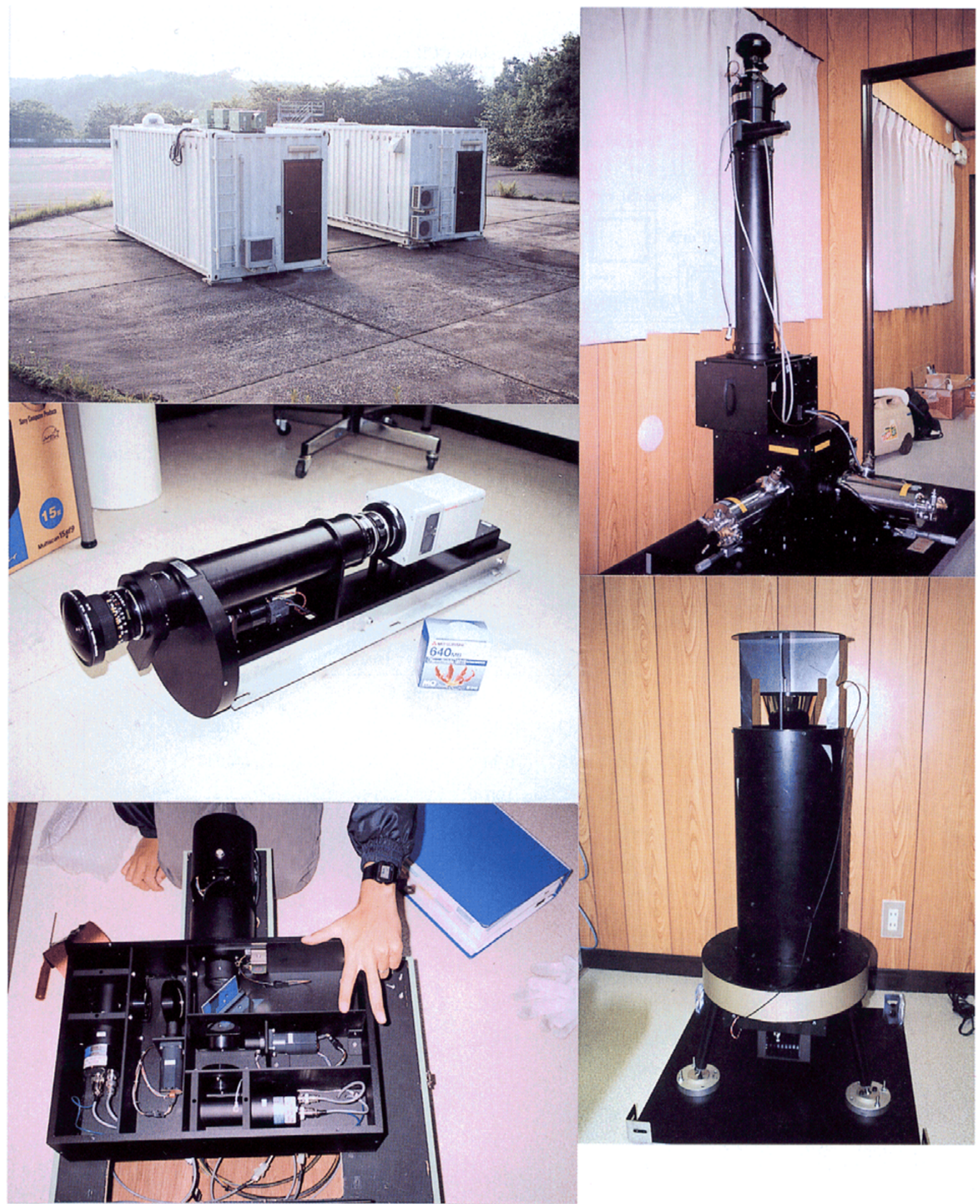

Fig. 2. Pictures of the instruments of OMTI. Two container houses (top left) with three photometers and several transparent domes on the roof, an all-sky camera (middle left), a meridian-scanning tilting photometer (bottom left), an imaging Fabry-Perot interferometer (top right), and a Spectral Airglow Temperature Imager (SATI, bottom right).

For airglow emissions with an intensity of $100 \mathrm{R}$, a 100 -s exposure provides $300-500$ counts per pixel. This amount is enough to discuss airglow patterns, since the read-out noise and the dark noise of the CCD detector are 10 (counts (r.m.s.)) and far less than 1 (counts/pixel/s), respectively. The typical exposure time for each emission line is also shown in Table 1.
The cameras are capable of detecting an airglow image by a 2-3 min exposure for $\mathrm{OI}, \mathrm{Na}$, and $\mathrm{O}_{2}$-band emissions and by a $15 \mathrm{sec}$ exposure for $\mathrm{OH}$ band emission. Simultaneous observation of at least three emission lines is possible using these cameras. One example of such an observation will be shown in Subsection 3.2. Coordinated multipoint observa- 


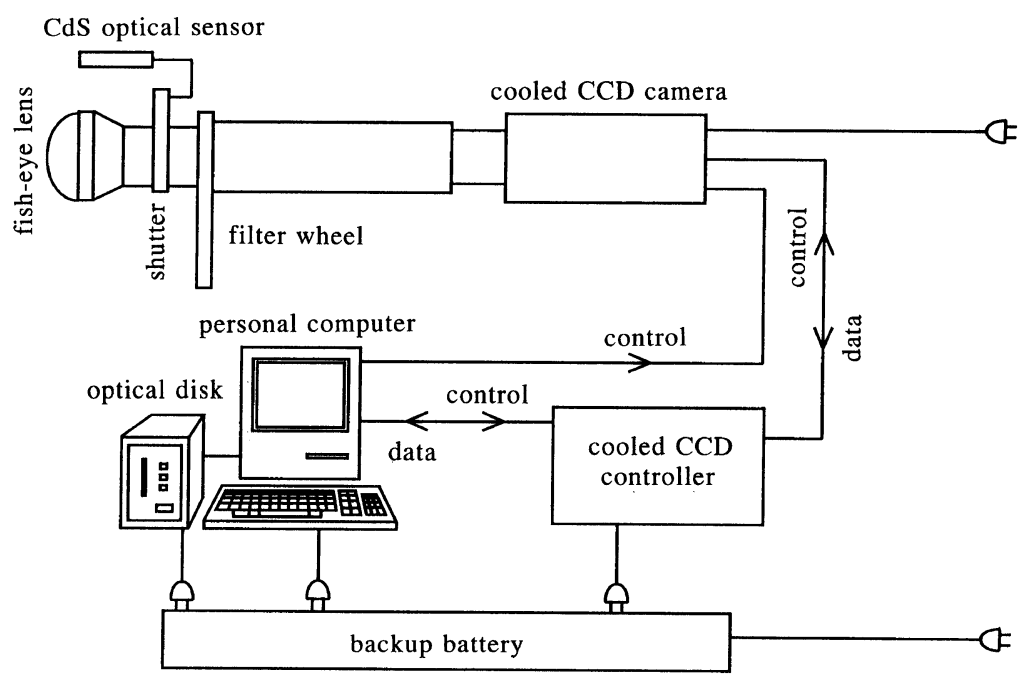

Fig. 3. Schematic diagram of the all-sky cooled CCD camera system with 5-position filter wheel. The camera operation is controlled by the personal computer. Image data are saved into the optical disk.

Table 1. Filter details, typical exposure times, and sensitivities for three all-sky nightglow imagers. The sensitivities are for (256, 256) pixel (around the center of image).

\begin{tabular}{|c|c|c|c|c|}
\hline Emission & $\begin{array}{c}\text { Wavelength } \\
(\mathrm{nm})\end{array}$ & $\begin{array}{c}\text { Bandwidth } \\
\text { (nm) }\end{array}$ & $\begin{array}{c}\text { Exposure } \\
(\mathrm{sec})\end{array}$ & $\begin{array}{l}\text { Sensitivity } \\
\text { (count/R/s) }\end{array}$ \\
\hline & \multicolumn{4}{|c|}{ camera \#1 } \\
\hline OI & 557.7 & 1.76 & 105 & 0.029 \\
\hline OI & 630.0 & 1.90 & 165 & 0.038 \\
\hline $\mathrm{OH}^{*}$ & $720-910$ & 190 & 15 & - \\
\hline $\mathrm{Na}$ & 589.3 & 1.83 & 105 & 0.032 \\
\hline \multirow[t]{2}{*}{ background } & 572.5 & 1.75 & 105 & 0.031 \\
\hline & \multicolumn{4}{|c|}{ camera \#2 } \\
\hline OI & 557.7 & 1.85 & 105 & 0.044 \\
\hline OI & 630.0 & 1.94 & 165 & 0.055 \\
\hline $\mathrm{OH}^{*}$ & $720-910$ & 190 & 15 & - \\
\hline $\mathrm{O}_{2}(0,1)$ & 865.0 & 10 & 105 & - \\
\hline \multirow[t]{2}{*}{ background } & 572.5 & 1.95 & 105 & 0.050 \\
\hline & \multicolumn{4}{|c|}{ camera \#3 } \\
\hline OI & 557.7 & 1.78 & 105 & 0.049 \\
\hline OI & 630.0 & 1.82 & 165 & 0.053 \\
\hline $\mathrm{OH}^{*}$ & $720-910$ & 190 & 15 & - \\
\hline $\mathrm{H} \beta$ & 486.1 & 1.92 & - & $0.005(465.1 \mathrm{~nm})$ \\
\hline background & 572.5 & 1.77 & 105 & 0.050 \\
\hline
\end{tabular}

${ }^{*}$ with a notch at $865 \mathrm{~nm}$ to suppress the $\mathrm{O}_{2}(0,1)$ emission.

tions are also possible using these cameras for $557.7 \mathrm{~nm}(\mathrm{OI})$, $630.0 \mathrm{~nm}(\mathrm{OI})$, and $\mathrm{OH}$ band emissions, since all the cameras have the same filters for these emissions.

\subsection{Tilting photometers}

The meridian-scanning tilting photometers No. 1 and 2 are built to measure mid-latitude airglow emissions of $\mathrm{OI}$ $(557.7 \mathrm{~nm}$ and $630.0 \mathrm{~nm})$ and $\mathrm{OH}$ bands with relatively nar- 


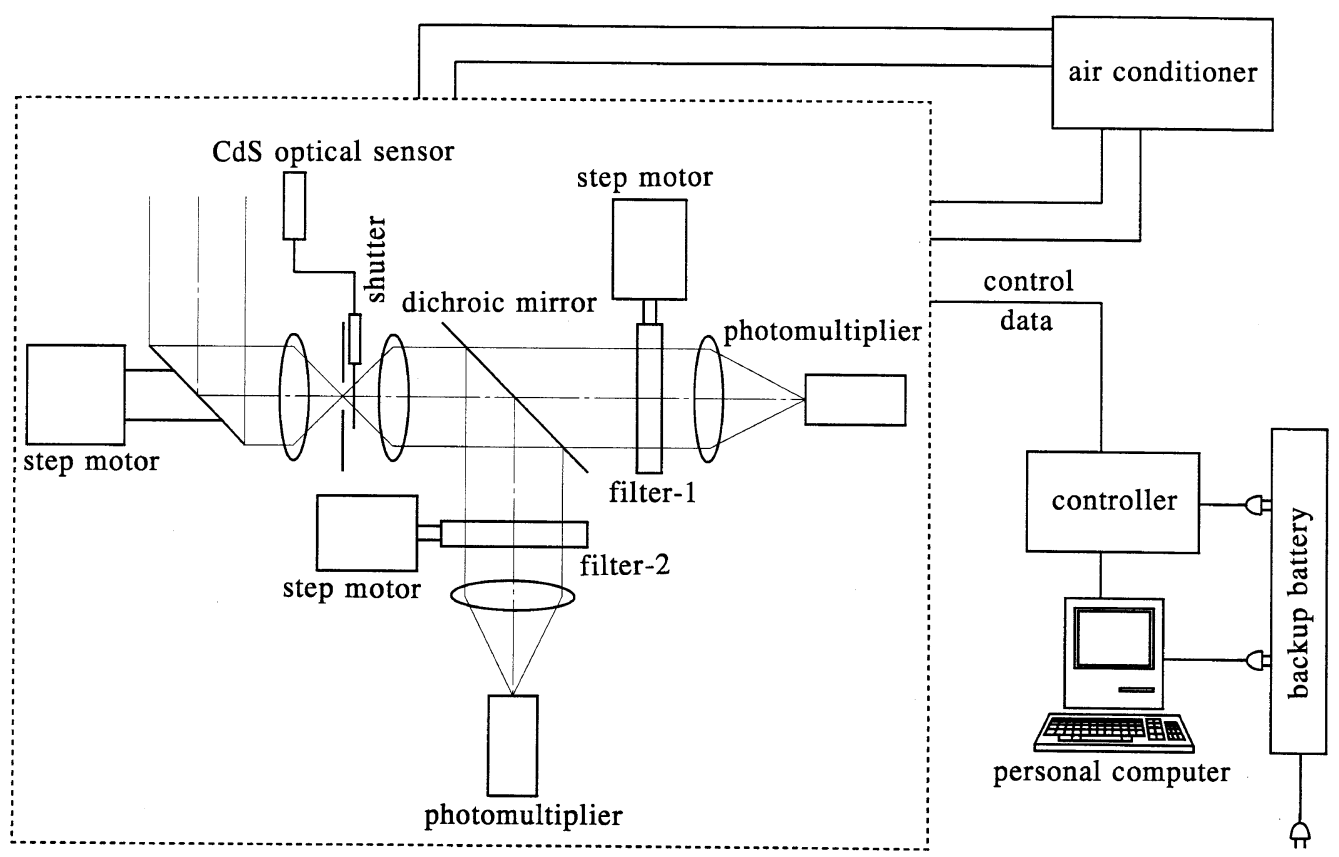

Fig. 4. Schematic diagram of the meridian-scanning tilting photometer system. Two airglow lines are measured simultaneously by separating the incident light using a dichroic mirror. The whole system is controlled by the personal computer.

Table 2. Filter and tilting details, sensitivities, and noise levels for three tilting photometers.

\begin{tabular}{|c|c|c|c|c|c|c|}
\hline Channel & Tilt angle & $\begin{array}{c}\text { Peak wavelength } \\
\text { (nm) }\end{array}$ & $\begin{array}{l}\text { Bandwidth } \\
\text { (nm) }\end{array}$ & $\begin{array}{l}\text { Sensitivity } \\
(\mathrm{mV} / \mathrm{R})\end{array}$ & $\begin{array}{l}\text { Noise level } \\
\text { (R) }\end{array}$ & Emission \\
\hline & \multicolumn{6}{|c|}{ photometer \#1 } \\
\hline 1 & $3.60^{\circ}$ & 846.5 & 0.53 & 0.23 & 35 & $\mathrm{OH}(6-2)$ \\
\hline 1 & $6.48^{\circ}$ & 845.8 & 0.87 & - & - & background \\
\hline 1 & $11.52^{\circ}$ & 843.0 & 1.43 & 0.092 & 87 & $\mathrm{OH}(6-2)$ \\
\hline 2 & $0.00^{\circ}$ & 558.5 & 0.41 & - & - & background \\
\hline \multirow[t]{2}{*}{2} & $6.48^{\circ}$ & 557.7 & 0.70 & 0.44 & 6.8 & OI \\
\hline & \multicolumn{6}{|c|}{ photometer \#2 } \\
\hline 1 & $3.60^{\circ}$ & 843.0 & 0.57 & 0.49 & 31 & $\mathrm{OH}(6-2)$ \\
\hline 1 & $7.20^{\circ}$ & 841.8 & 0.85 & - & - & background \\
\hline 1 & $10.80^{\circ}$ & 839.9 & 1.32 & 0.20 & 75 & $\mathrm{OH}(6-2)$ \\
\hline 2 & $0.00^{\circ}$ & 631.2 & 0.44 & - & - & background \\
\hline \multirow[t]{2}{*}{2} & $7.20^{\circ}$ & 630.0 & 0.80 & 0.089 & 112 & OI \\
\hline & \multicolumn{6}{|c|}{ photometer \#3 } \\
\hline 1 & $0.00^{\circ}$ & 486.6 & 0.42 & - & - & background \\
\hline 1 & $8.64^{\circ}$ & 485.1 & 0.71 & 13.25 & 2.3 & $\mathrm{H} \beta$ \\
\hline 2 & $0.00^{\circ}$ & 429.1 & 0.48 & - & - & background \\
\hline 2 & $7.92^{\circ}$ & 427.8 & 0.81 & 12.35 & 0.40 & $\mathrm{~N}_{2}^{+}(1 \mathrm{NG})$ \\
\hline
\end{tabular}

rower field of view, while the photometer No. 3 is built to measure weak emissions caused by energetic heavy particle precipitation during magnetic storms (e.g., Tinsley et al., 1984, 1986). Figure 4 is a schematic diagram showing one of the photometer system. The field of view of the $40 \mathrm{~mm}$ diameter front lens is $3^{\circ}$ for photometer No. 1 and 2 and $8^{\circ}$ for No. 3. The stepping motors for meridian scanning and filter tilting are controlled by the personal computer. The 


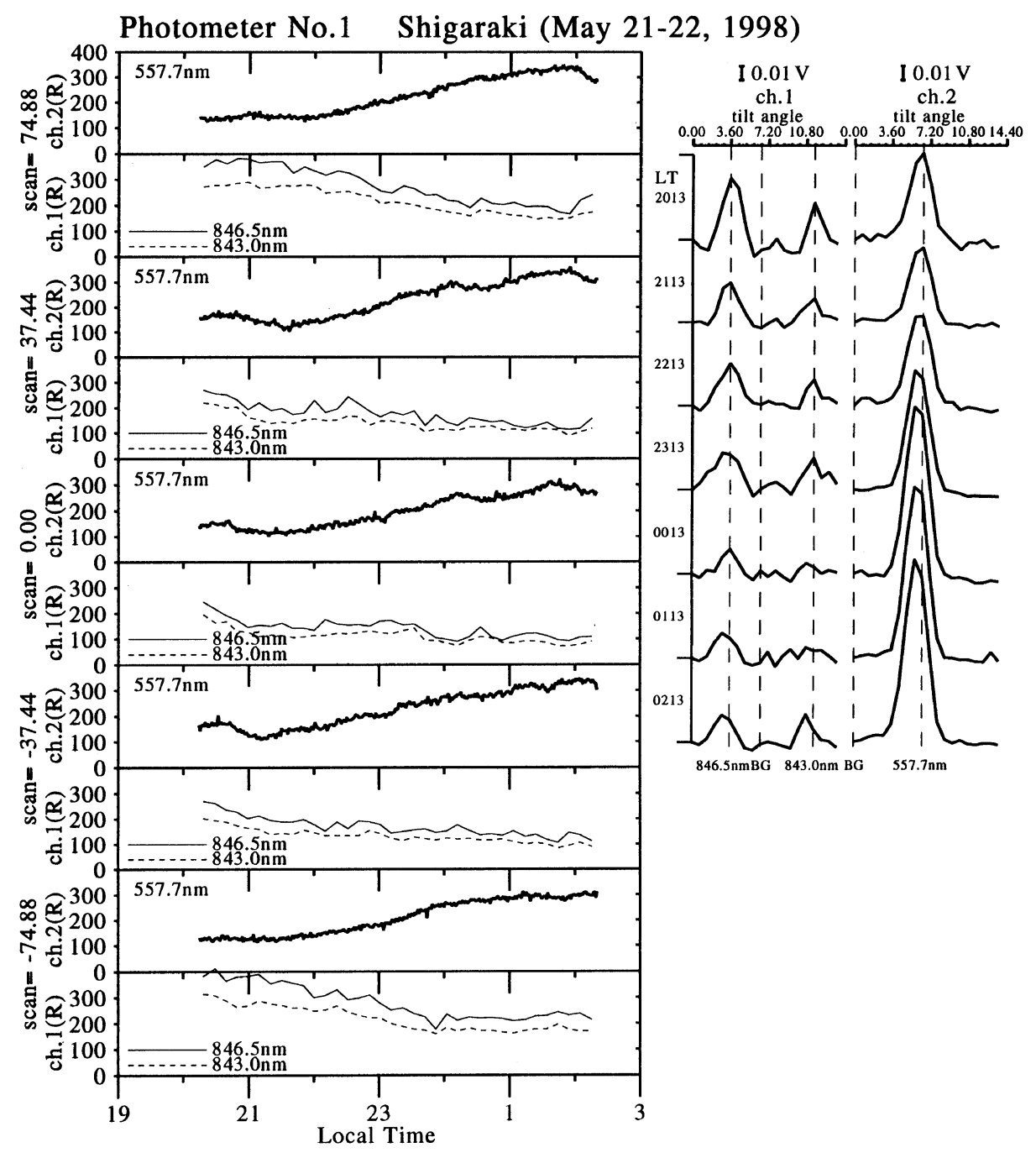

Fig. 5. Intensity variations of OI (557.7 nm) and OH Meinel (6-2) $(846.5 \mathrm{~nm}$ and $843.0 \mathrm{~nm})$ airglow emissions observed by the meridian-scanning tilting photometer No. 1 at Shigaraki $\left(35^{\circ} \mathrm{N}, 136^{\circ} \mathrm{E}\right.$ ), Japan on May $21-22,1998$. The meridian scanning is for five zenith angles from $-74.88^{\circ}$ (northward) to $74.88^{\circ}$ (southward). Line spectra obtained every hour by taking 1-min full-tilt data at the scan angle of $0^{\circ}$ (zenith) are also shown in the right side.

shutter is also controlled by the computer with a fail-safe system using the CdS optical sensor. The photomultipliers, Hamamatsu R636-10 (for No. 1 and 2) and R268 (for No. 3), are used as detectors. Low-pass filters with a cut-off period of $2 \mathrm{~s}$ (for No. 1 and 2) and $10 \mathrm{~s}$ (for No. 3) are used in the signal amplifier in order to reduce thermal noise from the photomultiplier. The temperature of the photometer is set at $20^{\circ} \mathrm{C}$ by the air conditioner. The whole system is backed up by a power supply that can run for more than $10 \mathrm{~min}$.

Filter and tilting details and sensitivities of the photometers are listed in Table 2. The sensitivities were obtained using calibration facilities at the National Institute of Polar Research, Japan. The time resolution of photometers No. 1 and 2 is $1 \mathrm{~min}(=4$ filter tilt $\times 5$ meridian scan $\times 2.5 \mathrm{~s}+$ dark current detection), while that of the photometer No. 3 is 10 $\min (=20$ filter tilt $\times 3$ meridian scan $\times 10 \mathrm{~s})$. Because the noise levels of the channels for the $\mathrm{OH}$ bands and the OI $(630.0 \mathrm{~nm})$ line are relatively high compared to the airglow intensity, data are further averaged for $10 \mathrm{~min}$ for these channels. Examples of the observed data will be shown in the next section.

\section{Observations}

\subsection{May 21-22, 1998}

The meridian-scanning tilting photometers started automatic observation of the airglow at Shigaraki $\left(35^{\circ} \mathrm{N}, 136^{\circ} \mathrm{E}\right)$, Japan in May 1998. Figure 5 shows intensity variations of OI $(557.7 \mathrm{~nm})$ and $\mathrm{OH}$ Meinel (6-2) (846.5 nm and $843.0 \mathrm{~nm})$ airglow emissions observed by photometer No. 1 during the clear night of May 21-22, 1998. The meridian scan is in the north-south direction. The spectra of these emission lines obtained every hour by taking full-tilt data of the filters at the meridian scan angle of $0^{\circ}$ (zenith) are also shown in the right side of Fig. 5. The noise levels of the OI curves and 10min averaged $\mathrm{OH}$ curves are small enough to discern hourly variation. It is clearly seen that the intensity of the $557.7 \mathrm{~nm}$ emission increases with increasing local time, while that of the $\mathrm{OH}$ bands decreases.

Figure 6 shows the intensity variations of the $\mathrm{O}_{2}$ Atmospheric (0-1) band and the $\mathrm{OH}$ Meinel (6-2) band emissions and rotational temperatures calculated from these emissions. These data are obtained by the SATI as an average over all azimuth angles at Shigaraki on the same night as that of Fig. 5. 


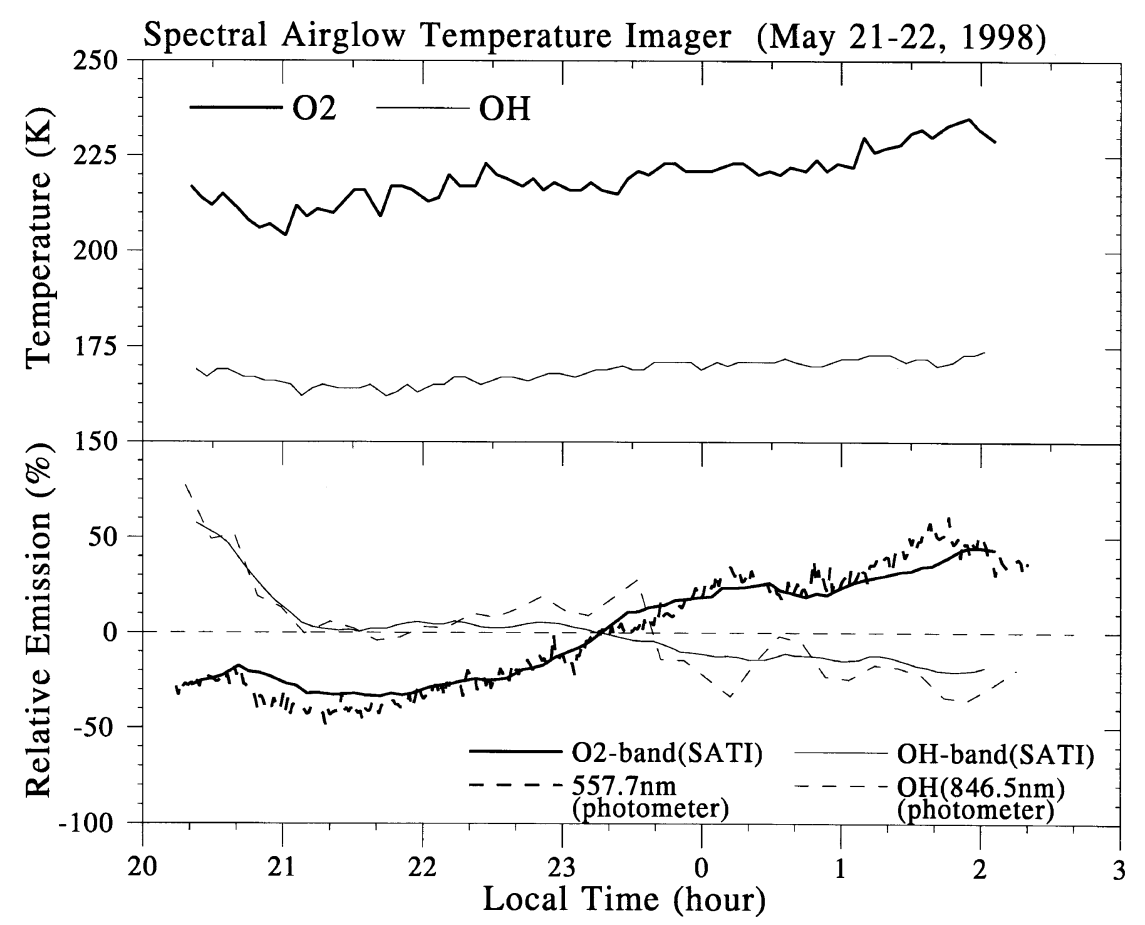

Fig. 6. Intensities and rotational temperatures of $\mathrm{O}_{2}$ Atmospheric (0-1) band and $\mathrm{OH}$ Meinel (6-2) band emissions measured by the SATI (average of all azimuth angles) at Shigaraki on May 21-22, 1998. The zenith photometer data in Fig. 5 are also plotted by dashed lines in the bottom panel.

The zenith photometer data in Fig. 5 are also plotted in the bottom panel. It is interesting that the intensities of $\mathrm{O}_{2}$ bands and $557.7 \mathrm{~nm}$ line measured by the SATI and the photometer, respectively, show fairly consistent variations. The $\mathrm{OH}$ band intensities measured by these two instruments fit quite well, though that by the photometer fluctuates after 23 LT. This fluctuation may be due to the different fields of view of the two instruments. The anti-correlation of the intensities of $\mathrm{O}_{2}$ and $\mathrm{OH}$ emissions is not seen in the temperature data. Both $\mathrm{O}_{2}$ and $\mathrm{OH}$ temperatures gradually increase from dusk to dawn.

Figure 7 shows intensity variations of the Doppler-shifted Hydrogen Balmer $\beta$ line $(485.1 \mathrm{~nm})$ and the $\mathrm{N}_{2}^{+}$First Negative line $(427.8 \mathrm{~nm})$ measured by photometer No. 3 on the same night as that of Fig. 5 (May 21-22, 1998). Emissions of these lines at mid-latitudes are caused by energetic heavy particle precipitation during magnetic storms. Since a magnetic storm did not occur on this day, no significant emission is seen in the data. One can see that the noise level of the photometer is less than $5 \mathrm{R}$ for both channels. The large negative intensities at the start of the observation around 20 LT are due to intense background sunlight, while the following weak emission of $\sim 4 \mathrm{R}$ for $20-21 \mathrm{LT}$ in $\mathrm{H} \beta$ is probably the geocorona.

\subsection{March 4, 1998}

During the first Japanese Planetary Scale Mesopause Observing System (PSMOS) campaign for January-March, 1998, we made a comprehensive observation of airglow emissions in the mesopause region. Four all-sky cameras (three from the OMTI and one from the Radio Atmospheric Science Center, Kyoto University) are used to obtain 3-dimensional structure of gravity waves through the airglow images.

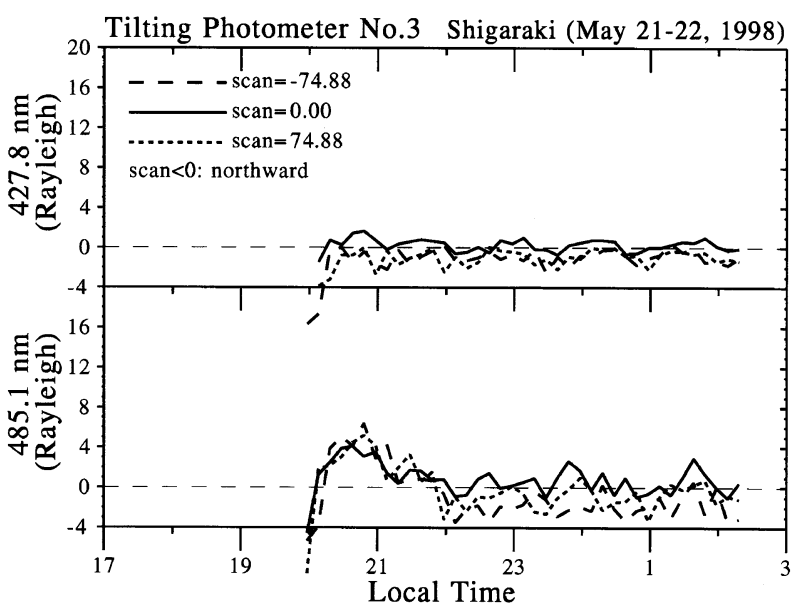

Fig. 7. Intensity variations of Doppler-shifted Hydrogen Balmer $\beta$ line $(485.1 \mathrm{~nm})$ and $\mathrm{N}_{2}^{+}$First Negative line $(427.8 \mathrm{~nm})$ measured by the meridian scanning tilting photometer No. 3 at Shigaraki on May 21-22, 1998. The meridian scanning is for three zenith angles from $-74.88^{\circ}$ (northward) to $74.88^{\circ}$ (southward).

Figure 8 shows an example of the observed airglow patterns in the four emissions OI $(557.7 \mathrm{~nm}, \sim 96 \mathrm{~km}), \mathrm{O}_{2}$ Atmospheric (0-1) bands ( 94 km), Na $(589.3 \mathrm{~nm}, \sim 90 \mathrm{~km}$, camera by the Kyoto University), and $\mathrm{OH}$ bands $(\sim 87 \mathrm{~km})$ on March 4, 1998. Background intensities of $\mathrm{Na}$ emission decrease significantly during the observed interval. The $\mathrm{OH}$ image is taken every $30 \mathrm{~s}$, while the images of other emissions are taken every $2 \mathrm{~min}$. Note that these are the first simultaneous observations of these four emissions using four all-sky cameras. 

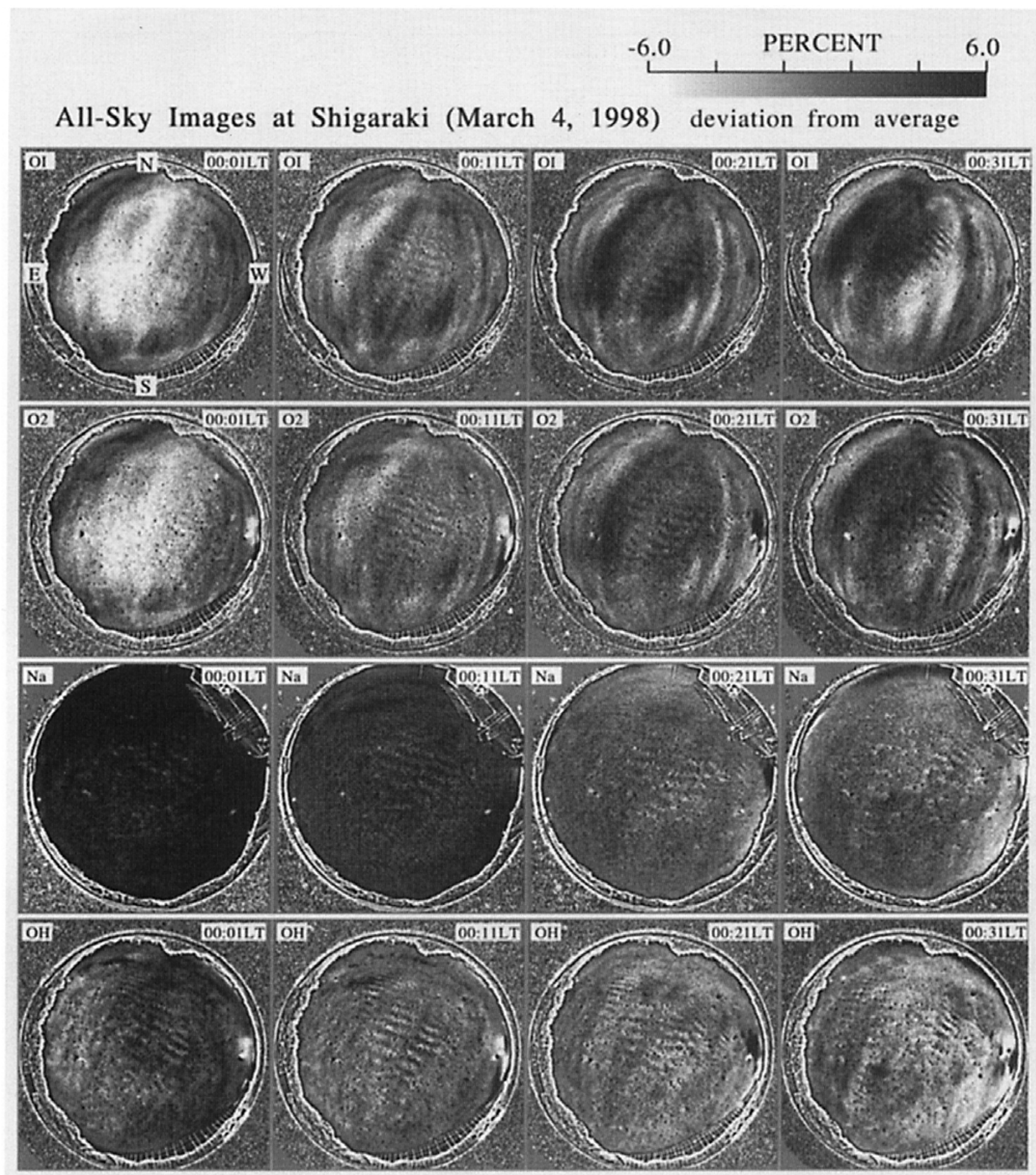

Fig. 8. All-sky airglow images at OI $(557.7 \mathrm{~nm}, \sim 96 \mathrm{~km}), \mathrm{O}_{2}$ Atmospheric $(0-1)$ bands $(\sim 94 \mathrm{~km}), \mathrm{Na}(589.3 \mathrm{~nm}, \sim 90 \mathrm{~km})$, and $\mathrm{OH}$ bands $(\sim 87 \mathrm{~km})$ observed at Shigaraki for 00:01-00:31 LT on March 4, 1998. The OH image is taken every $30 \mathrm{~s}$, while the images of other emissions are taken every 2 min. These images at four emission lines are taken at exactly a same time using four all-sky cameras. Upward is toward the north and leftside is toward the east. The images are deviations from the average image for 00:01-0031 LT.

Three kinds of wave structure are seen in these images. A schematic diagram of the wave structures seen in the OI image at 0021 LT is shown in Fig. 9. The first one is the large-scale "band" structure in the NNW-SSE direction which moves toward the ENE. The velocity of the motion is $\sim 160 \mathrm{~m} / \mathrm{s}$ in the OI images assuming an emission altitude of $96 \mathrm{~km}$. The horizontal wavelength of this structure is $\sim 100$ $\mathrm{km}$. This structure is clearly seen in the $\mathrm{OI}$ and $\mathrm{O}_{2}$ images but is not clear in the $\mathrm{Na}$ and $\mathrm{OH}$ images.

The second one is the large-scale EW structure which moves northward with a velocity of $\sim 80 \mathrm{~m} / \mathrm{s}$ in the OI images. This structure, which is more or less like a boundary between intense and weak emissions, is seen at the bottom edge of the OI and $\mathrm{O}_{2}$ images at $0001 \mathrm{LT}$ and around the center of the images at $0031 \mathrm{LT}$. This structure is relatively weak in the $\mathrm{Na}$ and $\mathrm{OH}$ images, but can be seen in the $0031 \mathrm{LT}$ images. 


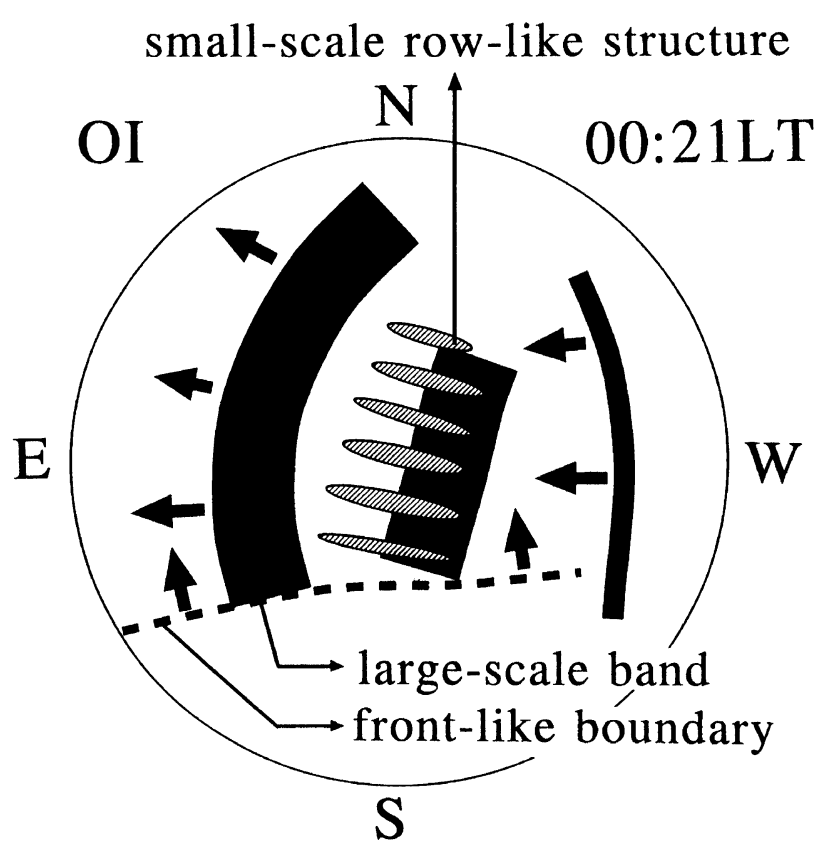

Fig. 9. Schematic diagram showing three kinds of wave structure seen in the all-sky image of the OI emission at 0021 LT in Fig. 8. The arrows indicate directions of the wave motion.

The third one is groups of small-scale waves which form row-like structures in the NW-SE direction. These row-like structures are seen in all four images around the center. The wavelength of the small-scale NE-SW waves in a row is $\sim 15$ $\mathrm{km}$. This structure is more distinct in the $\mathrm{OH}$ images than in the OI images.

\section{Discussion}

The noise levels of $\mathrm{OH}$ channels of the photometers No. 1 and 2 (31-87 R as listed in Table 2) are relatively high. By averaging 10 data as plotted in Fig. 5, the noise decreases to $1 / 3(\sim \sqrt{10})$ of these values. However, it is still difficult to calculate rotational temperature from the intensity data. Additional cooling will be needed for the photomultipliers.

On the other hand, the noise levels of the photometers are low enough to discuss diurnal intensity variations as shown in the comparison with data from the SATI. The good correlation observed between $\mathrm{OI}(557.7 \mathrm{~nm})$ and $\mathrm{O}_{2}$ Atmospheric (0-1) bands (Fig. 6) has been reported by previous researchers (e.g., Misawa and Takeuchi, 1977; Rodrigo et al., 1985). The trends of increasing $557.7 \mathrm{~nm}$ intensity and of decreasing $\mathrm{OH}$ band intensity are similar to those observed at Cachoeira Paulista $\left(23^{\circ} \mathrm{S}, 45^{\circ} \mathrm{W}\right)$ in May (Takahashi et al., 1984). The gradual increase of $\mathrm{O}_{2}$ rotational temperature is not similar to that observed at Bear Lake Observatory $\left(42^{\circ} \mathrm{N}, 111^{\circ} \mathrm{W}\right)$, but our May data were acquired later in the year than any of the Bear Lake data reported (Wiens et al., 1995).

The noise level of photometer No. 3 is less than $5 \mathrm{R}$ as shown in Fig. 7. Emission intensities at mid- and lowlatitudes by energetic heavy particle precipitation during magnetic storms are typically a few $\mathrm{R}$ for the $\mathrm{H} \beta$ line and a few hundred $\mathrm{R}$ for the $\mathrm{N}_{2}^{+}$(1NG) band (Tinsley et al., 1984). Thus, the noise level is comparable to the typical intensity for $\mathrm{H} \beta$, while it is low enough for $\mathrm{N}_{2}^{+}$(1NG) detection.

The all-sky images shown in Fig. 8 indicate that a variety of wave structures such as bands and row-like waves is observed at a mid-latitude of $35^{\circ} \mathrm{N}$. The large-scale band structures are seen only in the OI and $\mathrm{O}_{2}$ emissions. From the ALOHA-93 campaign observation at a tropical latitude of $21^{\circ} \mathrm{N}$, Taylor et al. (1995a) pointed out that wave structures are detected in significantly higher amount at OI altitudes ( $\sim 96 \mathrm{~km})$ and suggested ducted wave motions in the lower thermosphere. Similar mechanism may play a role at this latitude.

On the other hand, the small-scale row-like structure is observed simultaneously at all altitudes. Similar wave structures are reported by Taylor et al. (1995a). They also noted that this pattern is seen at all four wavelengths. However, the small-scale row-like structures in Fig. 8 are more prominent at the $\mathrm{OH}$ altitude than at the $\mathrm{OI}$ altitude, which is opposite to the observation by Taylor et al. (1995a).

The northward moving EW boundary structure is similar to the spectacular front event reported by Taylor et al. (1995b). Dewan and Picard (1998) suggested that such front passage is caused by the mechanism of a tidal bore in the mesopause region. A decrease of $557.7 \mathrm{~nm}$ intensity and an increase of $\mathrm{OH}$ intensity after the passage of the front is seen in the images of 0031 LT, which is also consistent with the observation by Taylor et al. (1995b). Small-scale wave structures observed in their images after the front passage is not clear in our case.

The three kinds of wave structures in Fig. 8 observed at the mid-latitude station is quite similar to those observed during the ALOHA-93 campaign at tropical latitudes. It is very interesting to note, however, that these waves appear in the same images.

\section{Summary}

We have developed the OMTI system in the SolarTerrestrial Environment Laboratory. The OMTI is capable of measuring wind, temperature, and 2-dimensional airglow pattern at multi-wavelengths simultaneously. Automated routine observations of airglow emissions by the cameras, the photometers, and the SATI were started from July 1998, May 1998, and December 1997, respectively, at Shigaraki, Japan. The operation of the Fabry-Perot interferometer has not been automated yet.

The $\mathrm{OH}$ rotational temperature from the photometer is still unreliable due to a high noise level, while diurnal variation of airglow intensity can be discussed from the photometer data. The photometer No. 3 has a capability enough to measure mid-latitude atmospheric emissions by heavy particle precipitation during magnetic storms. The SATI measures intensities and rotational temperatures of $\mathrm{OH}$ and $\mathrm{O}_{2}$ bands fairly well.

As shown in Fig. 8, simultaneous observation of airglow images at several wavelengths give us useful information to study vertical propagation of gravity waves. Short-period wave structures similar to those observed in the equatorial latitude are seen from the mid-latitude observation. We found an event during which large-scale bands, small-scale rowlike structures, and large-scale front passage occur simultaneously. 
Acknowledgments. We are grateful to M. Ishii, H. Fukunishi, H. Nakajima, S. Okano, Y. Takahashi, and M. Taguchi for their helpful comments and suggestions during the development of OMTI. R. Maekawa is greatly acknowledged for his skillful help to construct the automatic control software for the cameras. The all-sky cameras and the photometers were calibrated using facilities at the National Institute of Polar Research, Japan.

\section{References}

Conde, M. and R. W. Smith, Mapping thermospheric winds in the auroral zone, Geophys. Res. Lett., 22, 3019-3022, 1995.

Dewan, E. M. and R. H. Picard, Mesospheric bores, J. Geophys. Res., 103, 6295-6305, 1998.

Dyson, P. L., T. P. Davis, M. L. Parkinson, A. J. Reeves, P. G. Richards, and C. E. Fairchild, Thermospheric neutral winds at southern mid-latitudes: A comparison of optical and ionosonde $h_{m} F_{2}$ methods, J. Geophys. Res., 102, 27,189-27,196, 1997.

Fagundes, P. R., D. Gobbi, H. Takahashi, and Y. Sahai, Mesospheric energy loss rates by $\mathrm{OH}$ and $\mathrm{O}_{2}$ emissions at $23^{\circ} \mathrm{S}$, Ann. Geophys., 15, 797-804, 1997.

Hecht, J. H. and R. L. Walterscheid, Observations of the $\mathrm{OH}$ Meinel $(6,2)$ and $\mathrm{O}_{2}$ Atmospheric $(0,1)$ nightglow emissions from Maui during the ALOHA-90 campaign, Geophys. Res. Lett., 18, 1341-1344, 1991.

Hernandez, G. and R. G. Roble, Thermospheric nighttime neutral temperature and winds over Fritz Peak Observatory: Observed and calculated solar cycle variation, J. Geophys. Res., 100, 14,647-14,659, 1995.

Killeen, T. L. and R. G. Roble, Thermosphere dynamics: Contributions from the first 5 years of the Dynamics Explorer program, Rev. Geophys., 26, 329-367, 1988.

Meriwether, J. W., High-latitude airglow observations of correlated shortterm fluctuations in the Hydroxyl Meinel 8-3 band intensity and rotational temperature, Planet. Space Sci., 23, 1211-1221, 1975.

Misawa, K. and I. Takeuchi, Ground observation of the $\mathrm{O}_{2}$ (0-1) Atmospheric band at $8645 \mathrm{~A}$ and the [OI] 5577-A line, J. Geophys. Res., 82, 2410-2412, 1977.

Rees. D., A. Aruliah, T. J. Fuller-Rowell, V. B. Wickwar, and R. J. Sica, Winds in the upper mesosphere at mid-latitude: First results using an imaging Fabry-Perot interferometer, Geophys. Res. Lett., 17, 1259-1262, 1990.

Rodrigo, R., J. J. Lopez-Moreno, M. Lopez-Puertas, and A. Molina, Analysis of OI-557.7 nm, NaD, OH (6-2) and $\mathrm{O}_{2}\left({ }^{1} \Sigma_{g}^{+}\right)(0-1)$ nightglow emissions from ground-based observations, J. Atmos. Terr. Phys., 47, 1099-1110, 1985.

Shiokawa, K., Y. Katoh, M. Satoh, M. K. Ejiri, and T. Ogawa, Integratingsphere calibration of all-sky cameras for nightglow measurements, $A d v$.
Space Sci., 1999 (in press).

Takahashi, H., Y. Sahai, and P. P. Batista, Tidal and solar cycle effects on the $\mathrm{OI} 5577 \mathrm{~A}, \mathrm{NaD}$ and $\mathrm{OH}(8,3)$ airglow emissions observed at $23^{\circ} \mathrm{S}$, Planet. Space Sci., 32, 897-902, 1984.

Takahashi, H., Y. Sahai, B. R. Clemesha, D. M. Simonich, N. R. Teixeira, R. M. Lobo, and A. Eras, Equatorial mesospheric and F-region airglow emissions observed from latitude $4^{\circ}$ south, Planet. Space Sci., 37, 649655, 1989.

Taylor, M. J. and M. J. Hill, Near infrared imaging of Hydroxyl wave structure over an ocean site at low latitudes, Geophys. Res. Lett., 18, 1333 1336, 1991.

Taylor, M. J., M. B. Bishop, and V. Taylor, All-sky measurements of short period waves imaged in the OI $(557.7 \mathrm{~nm})$, Na $(589.2 \mathrm{~nm})$ and near infrared $\mathrm{OH}$ and $\mathrm{O}_{2}(0,1)$ nightglow emissions during the ALOHA-93 campaign, Geophys. Res. Lett., 22, 2833-2836, 1995a.

Taylor, M. J., D. N. Turnbull, and R. P. Lowe, Spectrometric and imaging measurements of a spectacular gravity wave event observed during the ALOHA-93 campaign, Geophys. Res. Lett., 22, 2849-2852, 1995 b.

Taylor, M. J., W. R. Pendleton, S. Clark, H. Takahashi, D. Gobbi, and R. A. Goldberg, Image measurements of short-period gravity waves at equatorial latitudes, J. Geophys. Res., 102, 26,283-26,299, 1997.

Taylor, M. J., J.-M. Jahn, S. Fukao, and A. Saito, Possible evidence of gravity wave coupling into the midlatitude $\mathrm{F}$ region ionosphere during the SEEK campaign, Geophys. Res. Lett., 25, 1801-1804, 1998.

Tinsley, B. A., R. P. Rohrbaugh, H. Rassoul, E. S. Barker, A. L. Cochran, W. D. Cochran, B. J. Wills, D. W. Wills, and D. Slater, Spectral characteristics of two types of low latitude aurorae, Geophys. Res. Lett., 11, 572-575, 1984.

Tinsley, B. A., R. Rohrbaugh, H. Rassoul, Y. Sahai, N. R. Teixeira, and D. Slater, Low-latitude aurorae and storm time current systems, J. Geophys. Res., 91, 11,257-11,269, 1986.

Wiens, R. H., S.-P. Zhang, R. N. Peterson, and G. G. Shepherd, MORTI: A mesopause oxygen rotational temperature imager, Planet. Space Sci., 39 1363-1375, 1991.

Wiens, R. H., S. P. Zhang, R. N. Peterson, and G. G. Shepherd, Tides in emission rate and temperature from the $\mathrm{O}_{2}$ nightglow over Bear Lake observatory, Geophys. Res. Lett., 22, 2637-2640, 1995.

Wiens, R. H., A. Moise, S. Brown, S. Sargoytchev, R. N. Peterson, G. G. Shepherd, M. J. Lopez-Gonzalez, J. J. Lopez-Moreno, and R. Rodrigo, SATI: A spectral airglow temperature imager, Adv. Space Sci., 19, 677$680,1997$.

K. Shiokawa (e-mail: shiokawa@stelab.nagoya-u.ac.jp), Y. Katoh, M. Satoh, M. K. Ejiri, T. Ogawa, T. Nakamura, T. Tsuda, and R. H. Wiens 